\section{Prevalência do papilomavírus humano (HPV) em Belém, Pará, Brasil, na cavidade oral de indivíduos sem lesões clinicamente diagnosticáveis}

\author{
Prevalence of human papillomavirus (HPV) in \\ Belém, Pará State, Brazil, in the oral cavity of \\ individuals without clinically diagnosable injuries
}

La prevalencia del virus del papiloma humano (VPH) en Belém, Pará, Brasil, en la cavidad oral de los individuos sin lesiones clínicamente diagnosticables

1 Universidade Federal do Pará, Belém, Brasil.

2 Universidade do Estado do Pará, Belém, Brasil.

Correspondência M. V. A. Araújo

Universidade Federal do Pará.

Av. Gentil Bittencourt 2132,

apto. 602, Belém, $P A$

66063-018, Brasil.

marizeli@ufpa.br

\begin{abstract}
This cross-sectional study aimed to determine $H P V$ prevalence in the oral cavity of individuals without clinically diagnosable lesions and to identify the respective HPV types. A total of 166 samples were analyzed from patients 18 years or older in the State of Pará, Brazil. Samples were collected by sterile brush scraping in the oral cavity. HPV detection used polymerase chain reaction (PCR). Infected samples were typed as HPV 6, 11, 16, 18, 31, 33, 35, 52, and 58. HPV was present in 40 samples (24.1\%). Three samples (7.5\%) were positive for HPV 6, five (12.5\%) for HPV 18, and one (2.5\%) for HPV 58.
\end{abstract}

Papillomavirus Infections; Mouth Diseases; Mouth
Marizeli Viana de Aragão Araújo 1 Helder Henrique Costa Pinheiro 1 João de Jesus Viana Pinheiro 1 Juarez Antônio Simões Quaresma 1,2 Hellen Thais Fuzii 1 Rita Catarina Medeiros 1

\section{Resumo}

Trata-se de um estudo transversal com o objetivo de verificar a prevalência do HPV na cavidade oral de indivíduos sem lesões clinicamente diagnosticáveis e quais são os tipos encontrados neles. Foram analisadas 166 amostras em pacientes maiores de 18 anos de idade, residentes no Estado do Pará, Brasil. As amostras foram coletadas por meio de raspado com escova estéril na cavidade oral. Para a detecção da presença do HPV, foi utilizada a técnica da reação em cadeia da polimerase (PCR). As amostras infectadas pelo HPV foram tipadas para HPV 6, 11, 16, 18, 31, 33, 35, 52 e 58. Os resultados encontrados indicaram a presença de HPV em 40 amostras (24,1\%). Três amostras (7,5\%) foram positivas para HPV 6; cinco (12,5\%), para HPV 18; e uma (2,5\%), para HPV 58.

Infecções por Papillomavirus; Doenças da Boca; Boca 


\section{Introdução}

Infecções pelo papilomavírus humano (HPV) são consideradas como a doença sexualmente transmitida mais comum, representando 450 milhões de pessoas infectadas na região anogenital, com incidência de $1 \%$ e prevalência superior a $50 \%$ no mundo 1 .

O HPV é universalmente aceito como agente causal do câncer de colo uterino e, em anos recentes, vem se especulando sua relação com o câncer de cavidade oral e orofaringe. O HPV 16 é o tipo mais comum associado ao câncer oral e ao de colo de útero, enquanto os tipos 6 e 11 são mais frequentes em lesões benignas e pré-malignas e raramente nas lesões neoplásicas da cabeça e do pescoço. Os achados comuns dos mesmos tipos de HPV (6, 11, 16 e 18) em mucosa oral e genital são um forte indicativo para a transmissão orogenital 2,3,4

Muitos estudos comprovam a associação do HPV com o câncer cervical. Outros foram publicados relacionando a presença de HPV no câncer oral. No Brasil e principalmente na Região Norte, esses estudos são escassos, assim este estudo se propõe a verificar a prevalência do HPV e os tipos mais prevalentes de HPV 6, 11, 16, 18, 31, 33, 35, 52 e 58 em indivíduos sem lesões clinicamente diagnosticáveis na cavidade oral, pois a realização de testes capazes de identificar o HPV pode ser um importante método para o diagnóstico precoce de lesões neoplásicas na cavidade oral e orofaringe.

\section{Método}

Este estudo caracteriza-se como transversal analítico. A amostra foi composta de raspado bucal de 166 indivíduos que procuraram atendimento na Faculdade de Odontologia da Universidade Federal do Pará, selecionados aleatoriamente, considerando o volume de atendimentos em um semestre. Os critérios de inclusão dos participantes foram não apresentar lesões clinicamente diagnosticáveis na cavidade bucal, residirem em Belém, Pará, e concordarem em participar da pesquisa após serem devidamente esclarecidos de seus objetivos. Considerando ser um estudo observacional e não necessitar da consideração do poder do teste, foram adotados grau de confiança de $99 \%$ e erro amostral absoluto de $10 \%$ para calcular o tamanho amostral. Como não existiam estudos prévios semelhantes no estado, considerou-se prevalência estimada de 50\% para efeito do cálculo do tamanho amostral.
A análise laboratorial para identificação viral foi realizada pela técnica de PCR (reação em cadeia da polimerase). Para a obtenção de DNA, foi coletado material em raspado com escova estéril (kit para coleta de colpocitologia oncótica) da mucosa do vestíbulo bucal bilateralmente, superfície dorsal e ventral de língua, palato duro, palato mole e assoalho bucal. O DNA foi extraído utilizando-se o kit PureLink Genomic DNA (Invitrogen, Carlsbad, Estados Unidos).

Para a pesquisa de HPV, foram utilizados dois procedimentos de PCR: um para detecção do DNA viral e outro para tipagem. As amostras positivas para HPV foram tipadas para os vírus tipos $6,11,16,18,31,33,35,52$ e 58.

PCR 1: realizada em termociclador Eppendorf (Hamburgo, Alemanha), utilizando GoTaq Green Master Mix (Promega, Madison, Estados Unidos). Para cada reação, foram utilizados $10 \mu \mathrm{L}$ de Mix, 8,2 de água e 0,8 $\mu \mathrm{L}$ de oligos MY9 e MY11 e 1,0 $\mu \mathrm{L}$ de DNA. A reação foi padronizada com um ciclo de desnaturação inicial de $94^{\circ} \mathrm{C}$ por 3 minutos e 40 ciclos da amplificação de PCR, com desnaturação em $94^{\circ} \mathrm{C}$ por 30 segundos, anelamento a $56^{\circ} \mathrm{C}$ por 30 segundos e extensão a $72^{\circ} \mathrm{C}$ por 30 segundos. Extensão final ocorreu a $72^{\circ} \mathrm{C}$ por 5 minutos com reação mantida a $10^{\circ} \mathrm{C}$. As amostras foram submetidas à eletroforese em gel de agarose a 1,5\% em TBE.

PCR 2: PCR em tempo real no StepOnePlus da Applied Biosystems (Foster, Estados Unidos), utilizando sondas específicas e kit Platinum qPCR SuperMix-UDG (Invitrogen, Carlsbad, Estados Unidos). A reação consistiu de 40 ciclos de desnaturação a $95^{\circ} \mathrm{C}$ por 30 segundos e anelamento e extensão a $60^{\circ} \mathrm{C}$.

Para controle da presença de DNA, as amostras foram submetidas à PCR para $\beta$ globina, nas mesmas condições usadas para HPV. Todas as reações foram realizadas utilizando-se um controle positivo de câncer de colo uterino e um controle negativo de amostra sabidamente negativa para PCR 1 e dois controles negativos, na PCR 2, para estabelecer confiabilidade à reação.

Este projeto foi aprovado em Comitê de Ética em Pesquisa, de acordo com as normas vigentes.

\section{Resultados}

Em relação à faixa etária, 43,4\% $(\mathrm{n}=72)$ tinham de 18 a 29 anos de idade; $37,4 \%(n=62)$, de 30 a 49 anos; $12,0 \%(\mathrm{n}=20)$, de 50 a 59 anos; e $7,2 \%(\mathrm{n}=$ 12), de 60 a 79 anos. A idade média foi de 35,9; e a mediana, de 33 anos.

Quanto ao sexo, 62,0\% ( $\mathrm{n}=103)$ pertenciam ao feminino; e 38\% ( $n=63$ ), ao masculino. Quan- 
do observada a cor da pele, $75,3 \%(n=125)$ eram pardos; 13,3\% ( $\mathrm{n}=22)$, negros; e 11,4\% $(\mathrm{n}=19)$, brancos. Tabagismo foi relatado por $6,6 \%$ da amostra; e o álcool, por 23,5\%.

A prevalência de indivíduos infectados pelo HPV foi de $24,1 \%(n=40)$ (Tabela 1).

As amostras infectadas pelo HPV foram submetidas à PCR para tipagem dos tipos $6,11,16$, $18,31,33,35,52$ e 58 , e observou-se a presença do HPV 6 em 7,5\% ( $=3)$; HPV 18, em 12,5\% ( $\mathrm{n}=$ 5); e HPV 58, em 2,5\% ( $=1$ ) (Tabela 2).

Os HPVs 11, 16, 31, 33, 35 e 52 não foram encontrados em nenhuma das amostras investigadas, totalizando 31 amostras positivas para HPV sem a presença dos tipos analisados (Tabela 2).

Não foi observada associação entre infecção pelo HPV e idade $(\mathrm{p}=0,24)$ e sexo $(\mathrm{p}=0,57)$. A associação entre infecção por HPV e cor da pele foi estatisticamente significante $(\mathrm{p}=0,03)$. Houve uma maior proporção de negros $(13,3 \%, \mathrm{n}=22)$ no grupo de não infectados $(16,7 \%, \mathrm{n}=21)$ que no de infectados $(2,5 \%, \mathrm{n}=1)$.

\section{Discussão}

O perfil da amostra corresponde às características da população paraense e dos pacientes que procuram atendimento odontológico. Mulheres procuram mais serviços de saúde por terem mais preocupação com seu bem-estar e estética que os homens e estarem vinculadas a tipos de ocupação com horários menos rígidos que os homens na sua maioria ${ }^{5}$. A cor da pele predominante no estado é parda, explicando a prevalência de $75,3 \%$.

Estudos envolvendo detecção de HPV na mucosa oral normal divergem na prevalência. Esquenazi et al. ${ }^{6}$ verificaram ausência de HPV nos 100 voluntários universitários pesquisados no Rio de Janeiro. Baixas prevalências foram encontradas por Ammatuna et al. 7 (3,3\%) e Migaldi

Tabela 1

Infecção por HPV nos indivíduos examinados a partir da raspagem da mucosa oral. Belém, Pará, Brasil, 2013.

\begin{tabular}{lcc}
\hline $\begin{array}{l}\text { Infecção por } \\
\text { HPV }\end{array}$ & $\mathbf{n}$ & $\%$ \\
\hline Sim & 40 & 24,1 \\
Não & 126 & 75,9 \\
Total & 166 & 100,0 \\
\hline
\end{tabular}

et al. 8 na Itália (1,2\%). Altas prevalências foram observadas por Zhang et al. ${ }^{9}$ na China (55\%) e Kristoffersen et al. 10 na Noruega (56\%).

A prevalência detectada nesse estudo (24,1\%) foi similar à de Llamas-Martinez et al. 11 na Espanha, 23,3\%. O HPV 16 não foi detectado, corroborando com os dados aqui encontrados.

Kristoffersen et al. 10 verificaram presença de HPV 6, 11 e 16. HPV 6 e 11 foram encontrados em duas amostras concomitantemente; HPV 6, em 11 amostras; HPV 11, em 7 amostras; e HPV 16, em uma.

Zhang et al. ${ }^{9}$ encontraram HPV 16 e HPV 18 em 13 e 11 amostras de um total de 22 positivas, respectivamente. Duas amostras apresentaram

Tabela 2

Prevalência de subtipos de HPV de interesse clínico em indivíduos infectados pelo vírus a partir da raspagem da mucosa oral. Belém, Pará, Brasil, 2013.

\begin{tabular}{|c|c|c|}
\hline $\begin{array}{l}\text { Subtipos de } \\
\text { HPV }\end{array}$ & $n$ & $\%$ \\
\hline \multicolumn{3}{|l|}{ HPV 6} \\
\hline Sim & 3 & 7,5 \\
\hline Não & 37 & 92,5 \\
\hline \multicolumn{3}{|l|}{ HPV 11} \\
\hline Sim & 0 & 0,0 \\
\hline Não & 40 & 100,0 \\
\hline \multicolumn{3}{|l|}{ HPV 16} \\
\hline Sim & 0 & 0,0 \\
\hline Não & 40 & 100,0 \\
\hline \multicolumn{3}{|l|}{ HPV 18} \\
\hline Sim & 5 & 12,5 \\
\hline Não & 35 & 87,5 \\
\hline \multicolumn{3}{|l|}{ HPV 31} \\
\hline Sim & 0 & 0,0 \\
\hline Não & 40 & 100,0 \\
\hline \multicolumn{3}{|l|}{ HPV 33} \\
\hline Sim & 0 & 0,0 \\
\hline Não & 40 & 100,0 \\
\hline \multicolumn{3}{|l|}{ HPV 35} \\
\hline Sim & 0 & 0,0 \\
\hline Não & 40 & 100,0 \\
\hline \multicolumn{3}{|l|}{ HPV 52} \\
\hline Sim & 0 & 0,0 \\
\hline Não & 40 & 100,0 \\
\hline \multicolumn{3}{|l|}{ HPV 58} \\
\hline $\operatorname{Sim}$ & 1 & 2,5 \\
\hline Não & 39 & 97,5 \\
\hline Total & 40 & 100,0 \\
\hline
\end{tabular}


ambos os tipos de HPV. Vale ressaltar que os autores pesquisaram apenas os tipos 16 e 18 e concluíram que a infecção por HPV é um evento comum na mucosa oral normal.

A associação entre infecção pelo HPV com faixa etária e sexo em indivíduos sem lesão na cavidade oral não foi estatisticamente significante neste estudo, apesar de a maioria da amostra ter menos de 50 anos e ser do sexo feminino, coincidindo com o encontrado por Llamas-Martinez et al. ${ }^{11}$.

Levando-se, em consideração, a importância dos agentes virais como fatores de risco, além do fumo e do álcool, para o desenvolvimento de câncer bucal e a mortalidade e sequelas que a doença pode causar na qualidade de vida das pessoas e inserção na sociedade, a realização de exames de biologia molecular para detecção dos agentes virais, especialmente o HPV, pode ser um excelente método para identificação de indivíduos com maior risco de desenvolvimento da carcinogênese oral, proporcionando diagnóstico precoce e facilitando o acompanhamento dos indivíduos infectados.

A concepção de que esses exames teriam alto custo não justifica sua exclusão como meio diagnóstico, já que o custo seria inferior aos efetuados com as despesas hospitalares advindas da cirurgia, radioterapia e quimioterapia, geralmente necessárias no tratamento do câncer bucal, pois os pacientes são detectados em estádio avançado, onerando o Sistema Único de Saúde, acrescido dos benefícios que podem trazer ao indivíduo, com um diagnóstico precoce, melhorando sua qualidade de vida.

\section{Resumen}

Se trata de un estudio transversal que tuvo por objetivo evaluar la prevalencia de HPV en la cavidad oral de sujetos sin lesiones orales clinicamente diagnosticables y qué tipos de HPV se encuentran en ellos. Se analizaron 166 muestras en pacientes mayores de 18 años de edad que viven en el estado de Pará, Brasil. Las muestras se recogieron por raspado con cepillo estéril en la cavidad oral. Para detectar la presencia de HPV se usó la técnica de Reacción en Cadena de la Polimerasa (PCR en inglés). En las muestras infectadas por el HPV se ejecutó una nueva PCR para los tipos HPV 6, 11, 16, 18, 31, 33, 35, 52 y 58. Los resultados indicaron la presencia de HPV en 40 muestras (24,1\%). Tres muestras $(7,5 \%)$ fueron positivas en HPV 6, cinco (12,5\%) en HPV 18 y una (2,5\%) en HPV 58.

Infecciones por Papillomavirus; Enfermedades de la Boca; Boca

\section{Colaboradores}

M. V. A. Araújo participou da concepção do projeto, análise e interpretação dos dados, redação do artigo e aprovação final da versão a ser publicada; sendo responsável por todos os aspectos do trabalho na garantia da exatidão e integridade de qualquer parte da obra. H. H. C. Pinheiro participou da concepção do projeto e análise e interpretação dos dados. J. J. V. Pinheiro participou da redação do artigo e revisão crítica relevante do conteúdo intelectual. J. A. S. Quaresma participou da revisão crítica relevante do conteúdo intelectual. $\mathrm{H}$. T. Fuzii foi responsável por todos os aspectos do trabalho na garantia da exatidão e integridade de qualquer parte da obra. R. C. Medeiros participou da concepção do projeto, análise e interpretação dos dados e aprovação final da versão a ser publicada.

\section{Agradecimentos}

Ao $\mathrm{CNPq}$ pelo apoio financeiro por meio do Edital MCT/CNPq/MS-SCTIE-DECIT/MS-SAS-DAB 32/2008. A Juliana Dias Aguiar e Nélida Cristina S. da Silva que colaboraram na obtenção da amostra. 


\section{Referências}

1. Foldvari M. HPV infections: can they be eradicates using nanotechnology? Nanomedicine 2012 8:131-5.

2. Xavier SD, Bussoloti Filho I, Carvalho JM, Framil VMS, Castro TMPG. Frequência de aparecimento de papilomavírus humano (HPV) na mucosa oral de homens com HPV anogenital confirmado por biologia molecular. Arq Int Otorrinolaringol 2007; 1:36-44.

3. Lo Muzio L, Campisi G, Giovannelli L, Ammatuna P, Greco I, Staibano S, et al. HPV DNA and survivin expression in epitelial oral carcinogenesis: a relationship? Oral Oncol 2004; 40:736-41.

4. Oliveira MC, Soares RC, Pinto LP, Costa LL. HPV e carcinogênese oral: revisão bibliográfica. Rev Bras Otorrinolaringol 2003; 4:553-9.

5. Carvalho G, Rosemburg CP, Buralli KO. Avaliação de ações e serviços de saúde. Mundo Saúde 2000; 1:72-88.

6. Esquenazi D, Bussoloti Filho I, Carvalho MGC, Barros FS. A frequência do HPV na mucosa oral normal de indivíduos sadios por meio da PCR. Braz J Otorhinolaryngol 2010; 1:78-84

7. Ammatuna P, Campisi G, Giovannelli G, Giambelluca D, Alaimo C, Mancuso S, et al. Presence of Epstein-Barr virus, cytomegalovirus and human papillomavirus in normal oral mucosa of HIV-infected and renal transplant patients. Oral Dis 2001; 7:34-40.
8. Migaldi M, Pecorari M, Forbicini G, Nanni N, Grottola A, Grandi T, et al. Low prevalence of human papillomavirus infection in the healthy oral mucosa of a Northern Italian population. J Oral Patho Med 2012; 41:16-20.

9. Zhang ZY, Sdek P, Cao J, Chen WT. Human papillomavirus type 16 and 18 DNA in oral squamous cell carcinoma and normal mucosa. Int J Oral Maxillofac Surg 2004; 1:71-4.

10. Kristoffersen AK, Enersen M, Kverndokk E, Sunde PT, Landin M, Solheim T, et al. Human papillomavirus subtypes in oral lesions compared to healthy oral mucosa. J Clin Virol 2012; 53:364-6.

11. Llamas-Martínez S, Esparza-Gómez G, CampoTrapero J, Cancela-Rodríguez P, Bascones-Martínez A, Moreno-López LA, et al. Genotypic determination by PCR-RFLP of human papillomavirus in normal oral mucosa, oral leukoplakia and oral squamous cell carcinoma samples in Madrid (Spain). Anticancer Res 2008; 28:3733-42.

Recebido em 28/Jul/2013

Versão final reapresentada em 29/Jul/2014

Aprovado em 21/Fev/2014 